\title{
International Scientific Publication in ISI Journals: Chances and Obstacles
}

\author{
Rawda Ahmed Omer ${ }^{1, *}$ \\ ${ }^{1}$ Curriculum and Instruction Department, College of Education, Najran University, KSA \\ *Correspondence: Curriculum and Instruction Department, College of Education, Najran University, KSA. E-mail: \\ rawda1165@yahoo.com
}

Received: October 15, 2015

Accepted: November 26, 2015 Online Published: December 15, 2015

doi:10.5430/wje.v5n6p81

URL: http://dx.doi.org/10.5430/wje.v5n6p81

\begin{abstract}
Recently, many universities have started to do their best to enhance their contribution in the scientific publication. Thus, researchers and faculty members have been offered many various financial and promotional incentives for publishing their papers in international journals, particularly the ISI ones. The present study aims to identify the opportunities and obstacles that faculty members at Najran University can obtain by publishing in ISI journals. In addition, distinction of the most important obstacles that can hinder such publication was another aim of the present study. Based on intensive review of related literature and a series of structured interviews, a questionnaire was developed, validated and verified. A stratified sampling method was used to choose participants of this study. Findings revealed that the contribution of ISI Journals to the identification of globally well-known journals, the development of participants' skills of refereed scientific publication in international journals, and the provision of positive attitudes towards scientific publication were the most important opportunities researchers have got. However, high standards of ISI journals, mastery of foreign languages, mainly English, and the originality of high intellectual topics were the most important barriers or obstacles that faculty members encountered when trying to publish their article papers in ISI journals. No statistically significant differences due to study variables regarding the opportunities were found. Nevertheless, significant differences due to specialization and previous knowledge of publication in ISI Journals were found.
\end{abstract}

Keywords: Scientific publication; Opportunities of ISI Publication, Obstacles of ISI publication; Electronic publication; Najran University

\section{Introduction}

The emergence of electronic journals has made a tremendous revolution in the fields of scientific and electronic publication. In light of this technological change, which helped widening the scientific research and increased beneficiaries, concepts of electronic publication have been affected, too. It has also brought about fundamental changes in the scientific communication between specialists and pushed scientific research forward. Scientific research and publication are very important, and because of this, many forums and conferences in the field of scientific research have recommended the interest in this field as it is a proof of countries' progress. The report of the regional seminar for scientific publication in 2012 called for paying attention to the applied researches that result in the interest of the community. It also stressed on the importance of scientific publishing in the field of humanities and social sciences, especially foreign languages in general and English in particular in order to promote Arab universities classification in the field of publishing in international journals. The scientific research is a prerequisite among the universities now, as some international rankings of universities are based on the amount of the scientific publications that have been published by faculty members, the type of publication vessels in which members' scientific production in various specialized areas is disseminated. Therefore, many universities have urged their members and encouraged them to spread their production in scientific journals, (Tartouri, 2010). Shirazi (2011) argues that quantity and quality of articles published in ISI journals can shed light on the scientific capabilities of a country and can be used as a yardstick to assess its development.

A well- known fact among all researchers says that publishing research papers and studies in influential journals enhances both academic position and job prospects in the future, whether scientific or not. Thus, the process of 
publication is a competitive one where numerous articles and research papers are presented whereas few are accepted. Since this competition is intensive, there should be a search for the main factors, which help or hinder the process of publishing in such prestigious scientific journals. Apart from its quality, Bol \& Hacker (2013) stress the importance of an article paper to be written well in order to reach intended audience. They admit that publishing in high quality journals is difficult and time consuming. But since a researcher wishes to contribute to research literature, he should be patient and tolerate going through many steps to get his paper published. Moghaddam and Hasanzadeh (2013) aimed to study the factors that inhibit women ISI research productivity. Findings showed that the most restraining factors that affect negatively scholarly articles publication by Iranian women were: shortcomings in the existing laws; stereotypes and beliefs concerning women; family work; social and cultural contingencies; child care and low collaboration with male colleagues. Hall, et. al. (2007, kyvik \& Olsen (2008), and Lissoni, et. al. (2011) agreed on the age of faculty member and the lack of newcomers to revitalize research as the main obstacles hindering scientific production and publication. Stack (2004) mentioned that the difficulty to balance between faculty member's professional and family life is another barrier. Hughes (1996) considered the low competitiveness between male and female colleagues as a main hindrance of scientific production and publication. Abramo, et. al. (2009) added that the lack of collaboration and communication among male and female colleagues and low human relations could also inhibit and limit publication. Fonseca et. al. (1997), and Barjak, (2006) elaborated on the fact that as well as success breeds success, failure always breeds nothing except failure. They all agreed that factors like physically low stamina; low self-confidence and shortcomings in existing laws are some of the barriers encountering scientific publication.

Kiewra (2008) states that researchers usually invest much time and effort to produce high quality research with the result that fair or unfair rejections can be received. Nevertheless, they have to be resilient and keep trying to publish their article papers. They should reflect failure into success. They should look at negative reviews as opportunities for improvement. Positive points should strengthen their work not disappoint them. Okoye (2010) explored to what degree academic librarians accept the use of Impact Factor (IF) to assess their academic performance. Findings showed that many authors believed that (IF) could be used to gauge the importance, collection and mission of journals, but not to assess the quality of research or publications. Few people understand (IF) and so its value and use to assess academic performance is questionable despite the defense provided by it advocators that there is no better alternative. Fiske and Fogg (1990) argued that publication in IF journal is a gain for any researcher although the reviewing phase is sometimes discouraging. All IF journals make their decision regarding publishing in accordance to the reviewers' viewpoints even though these reviewers have no sufficient experience in manuscript review. All what they have is consultation from colleagues who are earlier in this task and so quality of reviews vary greatly. Bol and Hacker (2013) opposed the view of Fiske and Fogg (1990) claiming that the ultimate goal of reviewing is to promote not to discourage high quality research/ study that will further the researcher's knowledge and understanding.

Cameron (2005) criticizes ISI journals for two main reasons. The fact that built-in bias of ISI's selection indicates the exclusion of many other foreign language journals leading to classifying most of journals in English in the top of the list of ISI journals with highest impact factors. The other reason for this criticism is the fact that many researchers in non-English speaking nations who wish to ensure greater amount of prestige find themselves obliged to publish in a foreign journal. Shirazi (2011) also aimed to identify barriers that academics face in publishing papers in ISI social/humanity science journals. Findings revealed that lack of proficiency in a foreign language; poor information technology infrastructure; inadequate access to international scientific databases and uncontrollable factors related to the nature of social science disciplines and political climate were the major barriers that inhibit publication in ISI journals. Lages, et al. (2014) investigated the reasons why Middle East and Africa-based studies in high-quality international journals are rare. Results proved that data access and data collection issues; diversity of the region; and lack of research support infrastructure were the most inhibiting research barriers. With regard to those barriers related to Middle East, data validity and reliability; language barriers; data collection issues; and availability of a network were the obstacles facing researchers there. In addition, editors and reviewers' low interest and limited knowledge were ranked high in both regions. Researchers in South Africa, Israel, and Turkey seemed to encounter less barriers than researchers in the rest of the two regions.

In conclusion, publishing in ISI journals is a profit for each researcher or faculty member. Their work will be globally marketed despite the many difficulties they may face. Therefore, the present study aims to look for the chances that researchers will inevitably get when publishing in one of those ISI journals. On the other side, the study will try to point out some of the obstacles, researchers may encounter. 


\section{Statement of the Problem}

Scientific publication is now considered the most important thing by which researchers exchange scientific knowledge between them. Through this publication, they share their productions to enrich the scientific and societal contributions. At present, scientific researches of high quality and intellectual originality have become a prerequisite of quality and university prosperity. There has been a global competition for the type of publication offered by each university through its researchers. Competition has also involved interest to publish in journals that have high impact factors. Publication in scientific journals that have high international impact factors has become a standard for university classification in accordance to the contribution of faculty members to publish in these ISI journals, the quality of published research, and its impact on researchers and knowledge community. Najran University, as well as other universities all over the world cares about the quality of its faculty members and their scientific research potentials. As a growing university, it seeks to occupy an advanced rank among nationally and internationally remarkable universities. It has instructed the deanship of scientific research to fund only those studies, articles, and researches that are published in ISI journals. Thus, researchers of the faculty members will not get the financial support unless their articles are published in the ISI journals.

Najran University, as well as other higher institutions all over the world, has taken seriously the matter of evaluating faculty members in accordance to how many article they have been published in ISI journals. Thus, faculty members at Najran University have begun looking forward to publishing their articles in ISI journals and consequently get the financial support. Hence, they have started to develop themselves with regard to their English language, which is the main language of such journals. They also have begun to search for these ISI journals and adapt their articles to the conditions and styles of the journal they have chosen. To do so, they have begun to encounter problems whether because of their language accuracy or conditions imposed by each journal. Therefore, the idea of the present study has been developed to investigate the most important difficulties as well as the most important benefits faculty members or researchers at Najran university may encounter.

\section{Importance of the Study}

Today, the country's extent of participation in generating and managing knowledge is accounted for as a main key criterion that measures its development and prosperity. Quantifying its knowledge wealth and production in a given year is one means to assess its position in knowledge management. The number of articles that scientists, researchers and faculty members publish in ISI journals often determines this position, (Shirazi, 2011). Evaluating faculty members' Academic performance based on their research papers in high-impact factor international journals is nearly spreading all over the world. Reactions towards this new trend have been rising in developing as well as developed countries. Nevertheless, research is still insufficient to enable decision takers to get clear picture, (Okoye, 2010). Therefore, findings of the present study can shed light on the opportunities researchers obtain by publishing in ISI journals. On the other hand, the study is hoped to make clearer the barriers that inhibit researchers from this kind of publication.

\section{Aims of the Study}

The present study seeks to:

1. identify the importance of publishing in ISI for faculty members,

2. identify the most important opportunities provided by publication in ISI for faculty members,

3. identify the most important difficulties researchers faced when publishing in IS, and

4. conclude a number of recommendations and suggestions, which may help researchers in Saudi universities, especially Najran University to publish in ISI journals.

\section{Questions of the study}

The present study aims to answer the following questions:

1. What are the main publication opportunities in ISI journals from the perspective of researchers at Najran University?

2. What are the main publication obstacles in ISI journals from the perspective of researchers at Najran University? 
3. What is the effect of variables like (gender - specialization- level of English language - papers published in ISI journals) on the views of researchers at Najran University with regard to the opportunities of publishing in ISI journals?

4. What is the effect of variables like (gender - specialization- level of English language - papers published in ISI journals) on the views of researchers at Najran University with regard to the obstacles of publishing in ISI journals?

\section{Theoretical Background}

Deopold (1979) defines scientific research as an accurate, organized and critical attempt to find solutions to the various problems that face and arise the anxiety and bewilderment of humans. it is an attempt to discover, explore, test, and develop knowledge. It aims to investigate and criticize knowledge then display it intelligently to move forward and contribute effectively to global civilization. Scientific publication is making available the researcher's scientific output of to the whole community via specific publication vessels. ISI publications are of various types such as paper and electronic publishing or through specialized institutions, which are nationally, regionally, or internationally refereed. Without scientific publication, neither true scientific progress nor reliable scientific research with documents results that benefit the community will be.

\subsection{Aims of Scientific Publications}

Harzing (2013) believes that Scientific Publications aims to:

1. contribute to the enrichment of knowledge society;

2. produce researches of high quality and impact on society;

3. contribute to community service by providing solutions to problems;

4. academic and vocational training on research writing in the area of specialization;

5. create a competition among researchers and universities regarding scientific and knowledge produce and

6. develop and discover new fields of knowledge.

\subsection{Importance of Global Scientific Publication}

Harzing (2013) believes that Scientific Publication is important because:

1. it contributes to the upgrading of human thought, which gives Scientific Publications the real value;

2. it is the product of varied research, which discusses impact factor problems;

3. it represents specialists' theses in the topics of human knowledge;

4. it opens prospects for new and ongoing developments in the current world in all fields, which in turn helps improve the standards of living;

5. it raises the level of the developing countries classification to developed ones in the scientific and technical side and

6. it raises many questions and inquiries, which represents a starting point for further studies.

6.3 What is ISI Journal Citation Reports on the Web?

ISI is a scientific party known as the Institute of Scientific Information. It was founded by Karfild Eugene Garfield in (1992) and then was purchased by Thomson Reuters Corporation (Thomson Reuters) for information, which sponsors it scientifically. Thomson Reuters offers services and integrated database. It saves citation databases covering thousands of academic journals and ensures the continuation of indexing Science Citation Index Service (SCI), Scientific citation guide, Social Sciences Citation Index (SSCI) guide the index of Social Studies of Science and Arts and Humanities Citation Index (AHCI), and the index of Arts and Humanities guide. It also publishes Journal Citation Reports (JCR), Annual index of the journal, which includes reports of the Impact Factor (IF) for each journal. ISI publishes a list of more than 14,000 journals in more than 60 countries. ISI Journal Citation Reports on the Web (JCR® Web) provides a systematic, objective means to evaluate critically the world's leading research journals. It offers a unique perspective for journal evaluation and comparison by accumulating and tabulating citation and article counts from virtually all specialties in the sciences, technology, and the social sciences. (Thomson Reuters, 2015). 


\subsection{What is Impact Factor (IF)?}

Impact factor is a quasi-qualitative indicator, which measures Journals' prestige and international visibility, (Maria \& Fernandez, 2002). It is also the accredited and approved party in the academic circles worldwide in this regard. Furthermore, it is a scale for the importance of the refereed scientific journals within different fields of research that reflects the extent by which new papers refer to and cite previous studies, (Thomson Reuters, 2015).

\subsection{What is the (ISI) Journal for Online Citation Reports?}

ISI Journal for online citation reports provides systematic and objective means to evaluate critically the world's leading research journals. It also offers a unique perspective to assess and compare the journal through the collection and tabulation of citation number of articles by all specialists in the fields of science, technology and social sciences. It also helps users to compare between journals and find out the most important ones for them, (Thomson Reuters, 2015). Garfield (1994) introduces Journal's Impact Factor saying that it is a measure of the frequency with which an average article in a journal has been cited in a particular year or period. It is calculated by dividing the number of current year citations to the source items published in that journal during the previous two years.

\section{Methodology}

The descriptive approach was used in the present study. The study instrument (questionnaire) was developed by reference to the related literature and previous studies. SPSS program was used for data analysis.

\subsection{Population \& Sample}

All faculty members at Najran University constituted the population of the present study. All researchers who had articles published and funded by the Deanship of Scientific Research were purposefully chosen and therefore constituted the sample. Participants' total number was (114) faculty members of various specializations.

\subsection{Instrument}

To accomplish the purposes of the present study, the researcher developed a two- dimension questionnaire. The first dimension included the expected opportunities while the second one involved all expected obstacles. It was validated through administering it to a group of arbitrators whose viewpoints were highly considered. Questionnaire's reliability was tested, too. Internal consistency was elicited through an exploratory sample consisted of (17) external participants according to Cronbach Alpha. Results are shown in table (1).

Table 1. Cronbach Alpha for Study Dimensions and the Whole Questionnaire

\begin{tabular}{cc}
\hline Study dimension & Alpha coefficient \\
\hline Publication opportunities & 0.89 \\
Publication obstacles & 0.91 \\
The whole questionnaire & 0.89 \\
\hline
\end{tabular}

\section{Results \& Discussion}

\subsection{Findings Related to the First Question}

To answer the first question, which aimed to identify the most important publication opportunities in ISI journals from the perspective of researchers at Najran University, the descriptive statistics for the questionnaire's items and dimensions were calculated. Table (2) shows the results. 
Table 2. Publication Opportunities in ISI Journals from the Perspective of Faculty Members

\begin{tabular}{|c|c|c|c|c|c|}
\hline No. & Items & M & SD & Degree & Rank \\
\hline 1. & It contributes to identification of globally well-known journals. & 2.91 & 0.34 & High & 1 \\
\hline 2. & $\begin{array}{l}\text { It develops the skills of refereed scientific publication in international } \\
\text { journals. }\end{array}$ & 2.91 & 0.32 & High & 2 \\
\hline 3. & $\begin{array}{l}\text { It provides the research with positive attitudes toward scientific } \\
\text { publication. }\end{array}$ & 2.82 & 0.43 & High & 3 \\
\hline 4. & $\begin{array}{l}\text { It can be used to evaluate the researcher in comparison with his colleagues } \\
\text { in the academic context. }\end{array}$ & 2.55 & 0.57 & High & 12 \\
\hline 5. & It facilitates effective communication with experts in the academic context. & 2.55 & 0.63 & High & 15 \\
\hline 6. & $\begin{array}{l}\text { It highlights the scientific work and its contribution to area of } \\
\text { specialization. }\end{array}$ & 2.80 & 0.52 & High & 4 \\
\hline 7. & It helps access reliable scientific data. & 2.70 & 0.53 & High & 8 \\
\hline 8. & It generates new scientific ideas and research attitudes. & 2.59 & 0.59 & High & 13 \\
\hline 9. & It speeds accessing relevant search results. & 2.50 & 0.68 & High & 17 \\
\hline 10. & It help reaching the latest published research and studies. & 2.64 & 0.60 & High & 11 \\
\hline 11. & It enables accessing published research and track them. & 2.50 & 0.64 & High & 18 \\
\hline 12. & It is reliable and ensures the intellectual property rights of the researcher. & 2.77 & 0.48 & High & 6 \\
\hline 13. & $\begin{array}{l}\text { It establishes international fame for the researcher allowing him many } \\
\text { opportunities. }\end{array}$ & 2.77 & 0.46 & High & 7 \\
\hline 14. & It encourages the researcher for co-authorship with other researchers. & 2.55 & 0.58 & High & 16 \\
\hline 15. & Quality control on research increases the value of scientific publications. & 2.70 & 0.50 & High & 9 \\
\hline 16. & $\begin{array}{l}\text { It helps the researcher to choose the best scientific journals through } \\
\text { comparing them in terms of their impact factors. }\end{array}$ & 2.80 & 0.48 & High & 5 \\
\hline 17. & $\begin{array}{l}\text { It contributes to the global advancement of scientific classification of the } \\
\text { institution to which the researcher belongs. }\end{array}$ & 2.68 & 0.54 & High & 10 \\
\hline 18. & It saves time and make it easy to access reliable data. & 2.48 & 0.68 & High & 19 \\
\hline 19. & It detects new theories that help to find solutions to existing problems. & 2.45 & 0.72 & High & 20 \\
\hline 20. & $\begin{array}{l}\text { It helps to access the important details that change the researcher's theories } \\
\text { and results. }\end{array}$ & 2.57 & $0 . .60$ & High & 14 \\
\hline & The whole questionnaire & 2.67 & $\mathbf{0 . 3 0}$ & High & \\
\hline
\end{tabular}

Table (2) reveals that researchers at Najran University agree to a very high degree that publication in ISI Journals provides them with many opportunities in this area $(\mathrm{M}=2.67)$. The table also is evident that the most important opportunities as perceived by those researchers are "it contributes to identification of globally well-known journals $(M=2.91)$; it develops the skills of refereed scientific publication in international journals $(M=2.91)$; and it provides the research with positive attitudes toward scientific publication $(\mathrm{M}=2.82)$."It highlights the scientific work and its contribution to area of specialization ( $\mathrm{M}=2.80)$; and it helps the researcher to choose the best scientific journals through comparing them in terms of their impact factors $(\mathrm{M}=2.80$ were also of similar importance. These results confirm that publication in ISI Journals contributes to the identification of globally prestigious journals, develops scientific and refereed publishing skills in international journals, and provides the researcher with positive attitudes towards scientific publication. It also plays a significant role in shedding light on the research work and the extent of its contribution to the field of specialization. It helps researchers to choose the best scientific journals through comparing between them in terms of their impact factors. Furthermore, all statements mentioned in table (2) were highly considered opportunities of publishing in ISI Journals. This, in turn indicates the awareness of faculty members at Najran University of the importance of publishing in ISI journals in addition to the opportunities that can be available for them by doing so.

\subsection{Findings Related to the Second Question}

To answer the second question, which aimed to identify the main publication obstacles in ISI journals from the perspective of researchers at Najran University, the descriptive statistics for the questionnaire's items and dimensions were calculated. Table (3) shows the results. 
Table 3. Obstacles of Publication in ISI Journals from the Perspective of Faculty Members

\begin{tabular}{|c|c|c|c|c|c|}
\hline No. & Items & M & SD & Degree & Rank \\
\hline 1. & It requires extensive knowledge about database Knowledge of the & & & High & \\
\hline & WEB & 2.54 & 0.77 & & 9 \\
\hline 2. & It requires high standards. & 2.78 & 0.48 & High & 1 \\
\hline 3. & It requires a knowledge of publication foreign languages, mainly & & & High & \\
\hline & English language. & 2.73 & 0.58 & & 2 \\
\hline 4. & It requires originality of high intellectual topics. & 2.70 & 0.50 & High & 3 \\
\hline 5. & $\begin{array}{l}\text { Weak research grants from the Deanships of Scientific Research } \\
\text { for researchers to publish in ISI Journals. }\end{array}$ & 2.32 & 0.84 & Moderate & 14 \\
\hline 6. & The absence of accredited guides for scientific journals data in ISI. & 2.23 & 0.81 & Moderate & 17 \\
\hline 7. & $\begin{array}{l}\text { Arbitrating and responding to the researcher require relatively a } \\
\text { long period. }\end{array}$ & 2.55 & 0.64 & High & 8 \\
\hline 8. & $\begin{array}{l}\text { It requires an advanced level of the writing style of the scientific } \\
\text { research. }\end{array}$ & 2.69 & 0.59 & High & 4 \\
\hline 9. & $\begin{array}{l}\text { The difficulty of choosing the appropriate scientific journal for } \\
\text { publication. }\end{array}$ & 2.34 & 0.65 & High & 13 \\
\hline 10. & $\begin{array}{l}\text { Some ISI journals ISI require content review professionals in the } \\
\text { publication language. }\end{array}$ & 2.51 & 0.71 & High & 12 \\
\hline 11. & It requires high research and computer skills. & 2.56 & 0.71 & High & 7 \\
\hline 12. & $\begin{array}{l}\text { Some journal use fake figures for their impact factors that trick the } \\
\text { researcher. }\end{array}$ & 2.20 & 0.72 & Moderate & 19 \\
\hline 13. & $\begin{array}{l}\text { The long time that an article takes to be published causes it to lose } \\
\text { some its scientific value and novelty. }\end{array}$ & 2.54 & 0.58 & High & 10 \\
\hline 14. & $\begin{array}{l}\text { Lack of Arab scientific journals included in the ISI, hinder the } \\
\text { publication of Arab researchers. }\end{array}$ & 2.59 & 0.72 & High & 5 \\
\hline 15. & $\begin{array}{l}\text { ISI journals do not give a real picture of the citation reality for } \\
\text { academicians publishing in these journals. }\end{array}$ & 2.32 & 0.67 & Moderate & 15 \\
\hline 16. & $\begin{array}{l}\text { It depends on the scientific journal citation for the last five years } \\
\text { only. }\end{array}$ & 2.31 & 0.62 & Moderate & 16 \\
\hline 17. & The researcher’s effort disappears after five years of publication. & 2.23 & 0.75 & moderate & 18 \\
\hline 18. & $\begin{array}{l}\text { The lack of an introductory training courses for faculty members } \\
\text { about publication in ISI journal }\end{array}$ & 2.57 & 0.69 & High & 6 \\
\hline 19. & $\begin{array}{l}\text { Publication opportunities of Humanitarian Research are less than } \\
\text { those for science research publication }\end{array}$ & 2.20 & 0.75 & Moderate & 20 \\
\hline 20. & $\begin{array}{l}\text { Publication in ISI Journals is a waste of the researcher's time in } \\
\text { terms of mobility among magazines. }\end{array}$ & 2.53 & 0.61 & High & 11 \\
\hline & The whole questionnaire & 2.47 & 0.37 & High & \\
\hline
\end{tabular}

Table (3) shows that Najran University faculty members' responses mean of the obstacles they face during publication in ISI journals is (2.47) indicating a high degree of difficulty. Mean scores are evident that the most important and critical obstacles faced by those researchers at Najran University are "Publication in ISI journal requires high standards $(M=2.78)$; knowledge of English language $(M=2.73)$ and the need for originality of high intellectual topics; $(M=2.70)$. The fact that it requires an advanced level of the writing style of the scientific research $(M=2.69)$ and the lack of Arab scientific journals included in the ISI $(M=2.59)$ were also of the most common obstacles. All these obstacles emphasize the fact that researchers at Najran University suffer a lot when trying to publish their papers in these ISI journals.

\subsection{Findings Related to the Third Question}

To answer the third question, which stated, what is the effect of variables like (gender - specialization- level of English language - papers published in ISI journals) on the views of researchers at Najran University with regard to the opportunities of publishing in ISI journals? T. test was used to compare between these means of participants' responses. Results are shown in table (4) below. 
Table 4. Differences in the Researchers' Views Regarding the Opportunities of Publication in ISI Journals

\begin{tabular}{lccccccc}
\hline \multicolumn{2}{c}{ Study Variables } & N & M & SD & T. value & Sig. & $(\boldsymbol{\alpha}=\mathbf{0 . 0 5})$ \\
\hline Gender & Females & 50 & 2.62 & 0.33 & -1.54 & 0.126 & Not significant \\
\multirow{2}{*}{ Specialization } & Males & 62 & 2.70 & 0.27 & & & \\
\multirow{4}{*}{ Language } & Social & 44 & 2.63 & 0.35 & -1.109 & 0.270 & Not significant \\
& Scientific & 68 & 2.69 & 0.26 & & & \\
\multirow{2}{*}{ Publication in ISI I } & Good & 52 & 2.63 & 0.36 & -1.36 & 0.176 & Not significant \\
& Excellent & 60 & 2.70 & 30.2 & & & \\
& Yes & 68 & 2.69 & 0.32 & 1.043 & 0.299 & Not significant \\
& No & 44 & 2.63 & 60.2 & & & \\
\hline
\end{tabular}

Table (4) illustrates that there is no statistically significant difference in the participants' responses with regard to the opportunities of publishing in ISI journals due to gender, Specialization, English language level, and papers published in ISI journals. The absence of any effect of these variables among faculty members at Najran University in accordance to the opportunities of publication in ISI journals is due to the fact that such publication provides the many opportunities regardless their specialization, gender, level of language, and whether they have publications in ISI journals or not. Publication in ISI journals is a real benefit to all without any other considerations since they are all fully aware of the importance of publishing in ISI journals.

\subsection{Findings Related to the Fourth Question}

To answer the fourth question that was about the effect of variables like (gender- specialization- level of English language - papers published in ISI journals) on the views of researchers at Najran University with regard to the obstacles of publishing in ISI journals, T. test was used to compare between these means of participants' responses. Results are shown in table (5) below.

Table 5. Participant researchers' Views regarding the Obstacles of Publication in ISI Journals

\begin{tabular}{cccccccc}
\hline \multicolumn{2}{c}{ Study variables } & N & M & SD & T. value & Sig. & $(\boldsymbol{\alpha}=\mathbf{0 . 0 5})$ \\
\hline Gender & Females & 50 & 2.47 & 0.41 & \multirow{2}{*}{0.017} & 0.986 & Not significant \\
& Males & 62 & 2.47 & 0.35 & & & \\
Specialization & Social & 44 & 2.58 & 0.34 & \multirow{2}{*}{2.46} & 0.015 & Significant \\
& Scientific & 68 & 2.40 & 0.38 & & & \\
Language & Good & 52 & 2.53 & 0.38 & \multirow{2}{*}{1.39} & & Not significant \\
& Excellent & 60 & 2.43 & 0.37 & & \multirow{2}{*}{0.014} & Significant \\
Publication In & Yes & 68 & 2.40 & 0.39 & -2.49 & & \\
ISI & No & 44 & 2.58 & 0.31 & & & \\
\hline
\end{tabular}

Table (5) reveals statistically significant differences in the participants' responses with regard to the obstacles of publishing in ISI journals due to specialization in favor of the scientific one, and papers published in ISI journals in favor of those who have already papers published in ISI journals. The difference that is due to specialization in favor of the scientific one can be explained by the fact scientific disciplines are of distinctive character in the field of scientific research in general, as in the medical, physical, chemical and engineering journals and other features. Research in these areas is characterized by authenticity, innovation and constructive ideas more than research in the field of human research, which is mostly analogy of human phenomena and behavior ...etc. Research in the scientific field is normally conducted in English and if we go back to all journals included in ISI list we find them specialized in the scientific field compared with journals of humanitarian research. This will inevitably reduce the degree of scientific researchers' suffering and obstacles in the fields of publishing in ISI because their opportunities are more than the opportunities of researchers in humanitarian fields.

As for the research published in ISI journals, which was in favor of researchers who have already published papers in ISI journals, difference is there because they have acquired much experience and many skills such as the speed and easiness in the search for ISI journals. They have broken the barrier of fear and dread of publication in ISI. They have acquired positive attitudes towards doing so and other aspects that can reduce their publication obstacles. Nevertheless, there was no statistically significant difference in the obstacles of publishing in ISI journals due to gender and level of English. That is, there is no effect of gender on the researchers' degree of suffering of the obstacles related to publishing in ISI journals. As well as to language variable, English is not a major concern to 
researchers since the researcher can refer to language specialists. Researchers can benefit from the professional sites, which offer proofreading and editing services at a very high level.

\section{Conclusion}

The main aim of the present study was to shed light on the importance of publishing in ISI journals for faculty members and other researchers. Two main issues were surveyed. The first main issue was to identify the most important opportunities provided by publication in ISI for faculty members and researchers. The other main issue was to understand the most important difficulties faced by researchers when publishing in ISI journals. Results showed that all participant groups in the present study believed that publication in ISI journals is very important as it develops to a large extent their research skills and knowledge of globally recognized journals in their areas of specialty. Moreover, the study revealed the most important obstacles that hinder the researchers' efforts to publish in such journals, like for example their English language proficiency and accuracy. Researchers' experience was also a critical factor in their success to publish in ISI journal.

\section{Recommendations}

In light of these results, the researcher recommends:

1. Other researchers to conduct similar studies but taking into account other variables.

2. Universities and publishers to provide faculty members and other researchers with lists of these ISI journals making clear their impact factors, place of publication, fees, ...etc.

3. Deanships of scientific research at universities to provide enough funding that can cover the Publication fees and make available the tools needed for search such as Internet, laptops, and data bases because all these ISI journals are online ones.

4. The necessity for universities to provide researchers and faculty members with editing, revising and online submitting services.

\section{References}

Abramo, G., D’Angelo, C. A., \& Caprasecca, A. (2009). Gender Differences in Research Productivity: A Bibliometric Survey on the Italian Academic System. Scientometrics, 79(3), 517-539. http://dx.doi.org/10.1007/s11192-007-2046-8

Bol, L., \& Hacker, B. J. (2013) . Publishing in High Quality Journals: Perspectives from Overworked and Unpaid Reviewers, J. Comput High Educ, 26, 39-53. http://dx.doi.org/10.1007/s12528-013-9073-7

Bordons, M., \& Gomez, F. E. (2002). Advantages and Limitations in the Use of Impact Factor Measures for the assessment of Research Performance in a Peripheral Country. Scientometrics, 53(2), 195-206. http://dx.doi.org/10.1023/A:1014800407876

Cameron, B. D. (2005). Trends in the Usage of ISI Bibliometric Data: Uses, Abuses, and Implications. Libraries and the Academy, 5(1), 105-125.

Deopold, V. D. (1979). Research Methods in Education and Psychology. Translated by Othman, S. A. (2010). Egypt: Anglo-Egyptian Library.

Fiske, D. W., \& Fogg, L. F. (1990). But the Reviewers are Making Different Criticisms of my Paper! Diversity and Uniqueness in Reviewer Comments. American Psychologist, 45, 591-598. http://dx.doi.org/10.1037/0003-066X.45.5.591

Fonseca, L., Velloso, S., Wofchuck, S., \& De Meis, L. (1997). The Importance of Human Relationships in Scientific Productivity. Scientometrics, 39(2), 159-171. http://dx.doi.org/10.1007/BF02457445

Garfield, E. (1994). The Thomson Scientific Impact Factor. Online. Retrieved on April 3, 2015, from http://thomsonreuters.com/business_units/scientific/free/essays/impactfactor/

Green, R., Davis, C., \& Corcoran, M. (2008). From the Desk of the Editor. Journal Impact Factors and (AJOT) American Journal of Occupational Therapy, 62, 7-8. http://dx.doi.org/10.5014/ajot.62.1.7 
Hall, B. H., Mairesse, J., \& Turner, L. (2007). Identifying Age, Cohort and Period Effects in Scientific Research Productivity: Discussion and illustration using Simulated and Actual Data on French Physicists. Economics of Innovation and New Technology, 16(1/2), 159-177. http://dx.doi.org/10.1080/10438590600983010

Harzing, A. W. (2011). The Publish or Perish Book, Part3, Melbourne, Australia: Tarmac Software Research Pty Ltd. Retrieved from http://www.harzing.com/popbook_p3.htm

Kiewra, K. A. (2008). Advice for Developing Scholars. Educational Psychology Review, 20(1), $79-86$. http://dx.doi.org/10.1007/s10648-007-9063-2

Kyvik, S., \& Olsen, T. B. (2008). Does the Aging of Tenured Academic Staff Affect the Research Performance of Universities? Scientometrics, 76(3), 439-455. http://dx.doi.org/10.1007/s11192-007-1767-z

Lages, C. R., Pfajfar, G., \& Shoham, A. (2015). Challenges in Conducting and Publishing Research on the Middle East and Africa in Leading Journals. International Marketing Review, 32(1), 52-77. http://dx.doi.org/10.1108/IMR-12-2014-0374

Lissoni, F., Mairesse, J., Montobbioy, F., \& Pezzoni, M. (2011). Scientific Productivity and Academic Promotion: A Study on French and Italian Physicists. Industrial and Corporate Change, 20(1), 253-294. http://dx.doi.org/10.1093/icc/dtq073

Melhem, S. M. (2015). Research Methodology in Education and Psychology. Amman, Jordan: Dar Maysarah for publication and distribution.

Moghaddam, A. I., \& Hasanzadeh, M. (2013). A Study of Factors Inhibiting Research productivity of Iranian Women in ISI. Scientomertics, 95(2), 797-815. http://dx.doi.org/10.1007/s11192-013-0980-1

Okoye, M. O. (2010). The Use of Impact Factor in the Appraisal of Academic Librarians in Nigeria, Library Philosophy and Practice (E-Journal). Retrieved from http://digitalcommons.unl.edu/cgi/viewcontent.cgi?article=1367\&context=libphilprac

Regional Seminar for Scientific Publication, (2012). A Report of the Regional Seminar for Scientific Publication in refereed Journals at Universities in the Arab World. Journal of Educational sciences, 25(1), 211-213.

Shirazi, A. (2011). Barriers Affecting Contribution of Developing Countries Social Scientists in ISI Indexed Journals. Information Management and Business Review, 3(1), 39-47

Stack, S. (2004). Gender, Children and Research Productivity. Research in Higher Education, 45(8), 891-920. http://dx.doi.org/10.1007/s11162-004-5953-z

Tartouri, H. M. (2010). Scientific Research: its Plan, Originality, and Consequences. Al-Quds Open University Journal for Research and Studies, 20, 81-115.

Thomson Reuters, (2015). ISI Journals Report Citation Reports. Retrieved from: http://thomsonreuters.com/en/products-services/scholarly 